\title{
Spatio-temporal distribution of flood disasters and analysis of influencing factors in Africa
}

\author{
Chan-juan $\mathrm{Li}^{1,2} \cdot$ Yuan-qing Chai ${ }^{1,2} \cdot$ Lin-sheng Yang ${ }^{1} \cdot$ \\ Hai-rong $\mathrm{Li}^{1}$
}

Received: 7 January 2016/ Accepted: 19 January 2016/Published online: 1 February 2016

(C) Springer Science+Business Media Dordrecht 2016

\begin{abstract}
To analyse inner- and inter-annual changes, disaster events of 55 countries in Africa from 1990 to 2014 recorded in the International Disaster Database (EM-DAT) were recounted by year and month and were reorganised in five different regions. Thematic maps of flood disasters in Africa between 1990 and 2014 were drawn using ArcGIS 9.3 to research the spatial distribution patterns of average annual flood frequency, total deaths, total affected, and damage. There were eight natural and socio-economic indicators chosen to explore the main factors influencing the spatio-temporal distribution of flood disasters in Africa, including precipitation, ENSO, runoff, forest coverage rate, reservoir capacity, per capita GDP, population, and urbanisation rate. Studies show that seasonal changes of flood disasters in various regions of Africa, except North Africa, are closely related to precipitation. Annual flood frequencies, from 1990 to 2014, showed a fluctuating upward trend and were in good agreement with ENSO years. In terms of spatial distributions, Ethiopia, Kenya, Somalia, Tanzania in eastern Africa, Nigeria in western Africa, and Libya, and Sudan in northern Arica are flood-prone countries, and main factors influencing spatial disparities include runoff, per capita GDP, population, and urbanisation rate.
\end{abstract}

Keywords Africa $\cdot$ Flood disaster $\cdot$ Spatio-temporal distribution $\cdot$ Influencing factors

Lin-sheng Yang

yangls@igsnrr.ac.cn

1 Key Laboratory of Land Surface Pattern and Simulation, Institute of Geographical Sciences and Natural Resources Research, Chinese Academy of Sciences, A11, Datun Road, Chaoyang District, Beijing 100101, People's Republic of China

2 University of Chinese Academy of Sciences, Beijing 100049, People's Republic of China 


\section{Introduction}

Flood disaster is one of the most serious natural disasters and is mainly due to natural environmental causes, including characteristics of climate, hydrology and vegetation, and human activities, such as vegetation destruction, reclaiming land from lakes, occupation of river and flood diversion zones in flood-prone areas. Climate anomalies, such as climate warming and precipitation inter-annual variability, and human activities may affect hydrological processes and worldwide allocation patterns of water resources and then induce changes in flood frequency and intensity (Jiang et al. 2006; Kabanda and Palamuleni 2013; Veijalainen et al. 2010; Vormoor et al. 2014). Flood disasters exhibit obvious inner-annual changes because of seasonal changes in precipitation and river flow (He et al. 2009). When precipitation increases, river water levels will rise: this can lead to flooding. Global scale influences such as the El Niño and La Niña phenomena may lead to irregular inter-annual variability of flood disasters in Africa. Regional disparities in flood disasters are affected by climate, hydrology, land cover, economy, and population in different countries. In 2009, the Global Assessment Report on Disaster Risk Reduction pointed out that the distribution of global disaster risk was very uneven, and there was a close link between the disaster risk and poverty, which meant that disaster deaths and reconstruction of infrastructure and facilities were mainly taking place in poor countries (UNISDR 2009).

Statistical data from the international disaster database, EM-DAT, indicate that natural disasters in Africa are various, mainly including droughts, floods, and epidemics: there is a significant correlation between flooding and epidemics of infectious diseases (Milly et al. 2002). The direct harm of flood disasters to human health lies in their causing casualties, while indirect harms include changes in the ecological environment, causing migration and expansion of natural foci, which may cause outbreaks of infectious diseases. This research selected the highest frequency natural disasters in Africa, floods, as its research object, revealing their temporal and spatial variations. Besides, there were several related natural and socio-economic indicators selected for quantitative analysis of these factors and how they affected the spatial and temporal patterns of flood disasters, including precipitation, ENSO, runoff, forest coverage, reservoir capacity, population, per capita GDP, and urbanisation rate. Study results may provide basis and guidance for research into disaster control, control of epidemics of infectious diseases, and medical assistance thereafter, in Africa.

\section{Data and methods}

\subsection{Data resources}

Due to no data or lack data in the Sahrawi Arab Democratic Republic (West Sahara) and Republic of South Sudan, the study areas concern 55 countries in Africa, including 49 continental countries and 6 island countries. Republic of South Sudan was independence as a country in July 2011, so we studied South Sudan and Sudan together in this paper.

The numbers of flood disasters by month and year as well as deaths, people affected, and total losses in African countries from 1990 to 2014 were selected from the international disaster database, EM-DAT, managed by the Centre for Disaster Epidemiological Studies of the University of Leuven, Belgium. Oceanic Niño Index (ONI) and Southern Oscillation Index (SOI) data from 1990 to 2014 come from the National Oceanic and 
Atmospheric Administration (NOAA). Average monthly precipitation and annual runoff in African countries were extracted from raster data obtained from Research Program on Climate Change, Agriculture and Food Security (CCAFS) and World Water Assessment Programme (WWAP), respectively. Forest coverage rate and reservoir capacity during 1990 and 2014 were obtained from the human-earth system subject database in China and statistical databases of the Food and Agricultural Organization of the United Nations (FAOSTAT), respectively. Other socio-economic data, including population, per capita GDP, and urbanisation rate, come from the World Bank Database.

\subsection{Statistical methods}

According to the natural disaster records in the EM-DAT database, this research established a spatio-temporal database of flood disasters in Africa from 1990 to 2014 and preprocessed data and drew charts using Origin 8.5 and MS-Excel ${ }^{\mathrm{TM}} 2007$ to analyse withinyear and inter-annual variations in flood disasters. Besides, the linear fitting model in the Origin 8.5 software was used to analyse the time series variation trend of flood disaster frequencies. Secondly, spatial patterns of flood disaster elements, including frequency, death, influenced people and losses, were analysed using ArcGIS 9.3 software by the Natural Breaks classification method. Lastly, to explore the main factors influencing the temporal and spatial distributions of flood disasters in African countries, Pearson correlation analysis was chosen to research relationships between flood disasters and the selected indicators as mentioned above.

\section{Results and discussion}

\subsection{Temporal change and influencing factors analysis of flood disasters}

\subsubsection{Within-year changes and influence factors}

The monthly frequencies of flood disasters are consistent with annual variations in precipitation, which may be the main factor affecting flood disaster occurrences by month in different regions of Africa. Flood disasters are concentrated in August in Africa on the whole and are evenly distributed in other months. Northern and eastern Africa are mainly located within the Nile basin, and floods are mainly found in 8-10 months therein. The two rainy seasons in most of East Africa, respectively, from March to May and from September to November mean that there are two other peaks for flood disasters in April and October, but not in August. Flood occurrences in Burundi, Djibouti, and Rwanda peaked in April, and the peaks of floods in Kenya appear in April and October, separately. The spatial distributions of temperature and precipitation are uneven in Ethiopia due to large altitude variations, and the longer rainy season runs from June to September, while the shorter one runs from February to May. So flood disasters are more common in August and April in Ethiopia, leading to the emergence of a peak in August in East Africa. Southern Africa's major rivers are the Zambezi and Orange, most of which lie in a tropical steppe climate with clear wet and dry seasons. The monthly dynamic trend in flood disasters is consistent with precipitation and is mainly concentrated in 12-3 month periods. The southern part of western Africa has a tropical rain forest climate, and the northern part has a tropical steppe climate, where the rainy wet season coincides with a hot summer. Floods are mainly 
concentrated in June to September, when the precipitations and the flows are greater. Central Africa lies mainly in the Congo River Basin with its mostly tropical rain forest climate: flood disasters are more common in August to October with abundant rainfall therein (Fig. 1).

\subsubsection{Inter-annual changes and influencing factors}

Floods have occurred 744 times during 1990-2014, including 369 times in which deaths occurred (accounting for half of the total). Figure 2 illustrates that the occurrences of flood disasters in Africa as a whole, and its various regions, had a fluctuating upward trend from 1990 to 2014, and the coefficients of variation (CV) were 0.56, 0.73, 0.69, 0.71, and 0.68 in North, East, Southern, West, and Central Africa, respectively. This indicated that the annual variation was greatest in West Africa and least in North Africa. The red lines represent linear fitting results of flood disaster frequencies in different regions: the slopes were $0.115,0.438,0.496,0.152$, and 0.354 , respectively, also indicating that flood disasters increased the fastest in West Africa. The El Niño/Southern Oscillation dynamic (ENSO) is the strong signal of global climate anomalies, so the El Niño/La Niña years and Southern Oscillation Index were selected to analyse the impact of climate anomalies on inter-annual variability of flood disaster occurrences. According to the standard developed by ENSO monitoring groups, Oceanic Niño Index (ONI) data provided by the US National Oceanic and Atmospheric Administration and a literature search, there are six El Niño years (1991, 1992, 1997, 2002, 2004, and 2009) and six La Niña years (1998, 1999, 2000, 2008, 2010, and 2011) during 1990-2014. Prior studies showed that although the relationship between ENSO and precipitation is nonlinear, global land annual precipitation is less offset in most El Niño years, while it is more offset in La Niña years (Meque and Abiodun 2014; Sasaki et al. 2015; Tang and Yuan 2010). Annual frequencies of flood disasters showed several
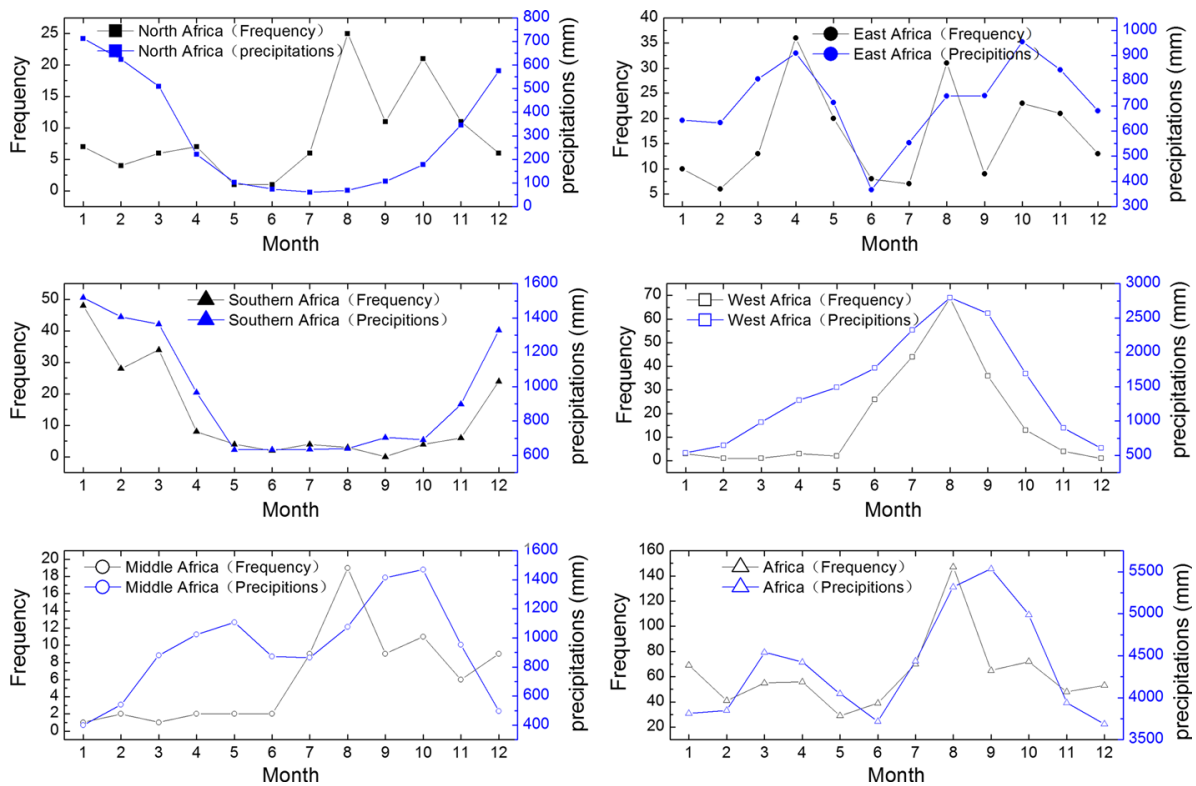

Fig. 1 Within-year variations of flood disaster frequency and precipitation between 1990 and 2014 

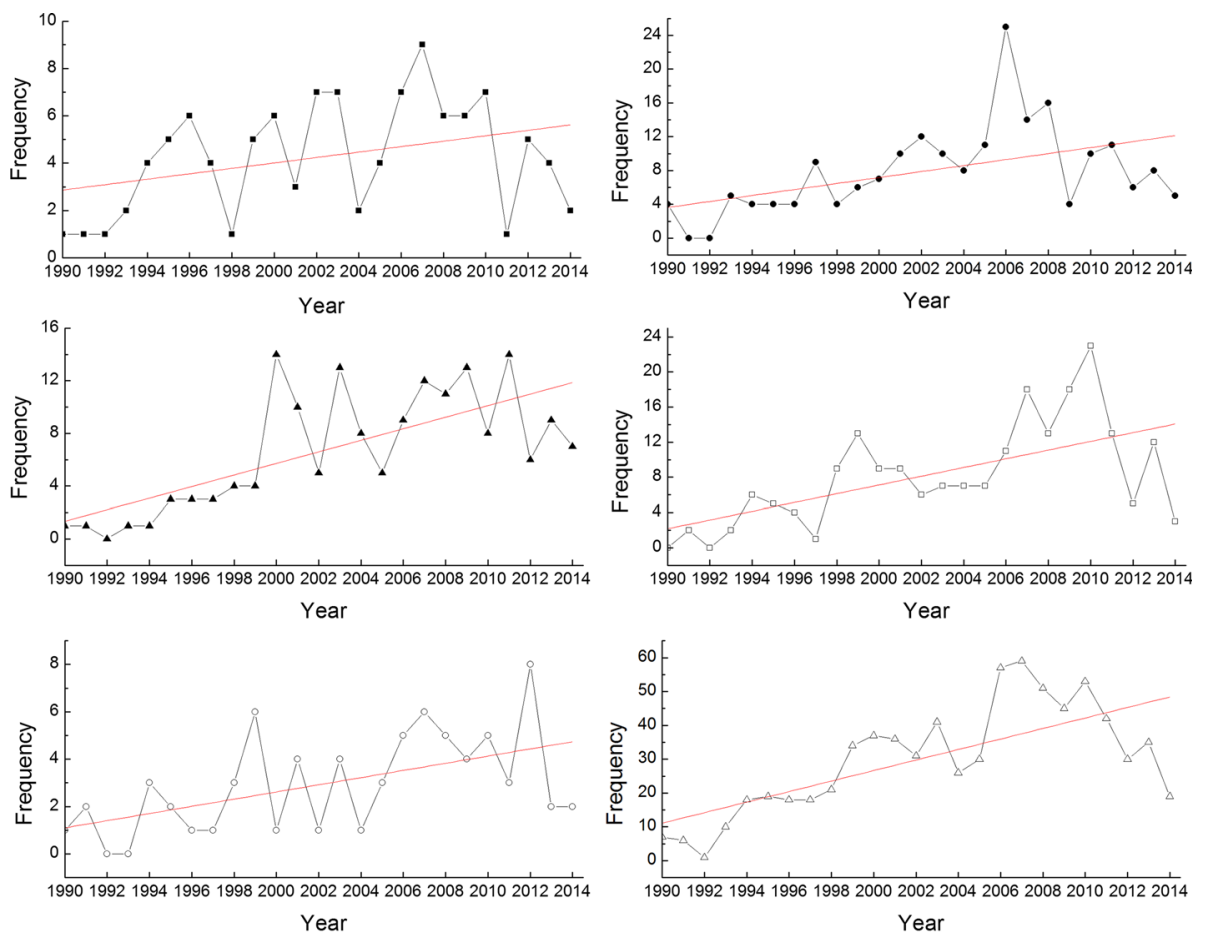

- North Africa

- East Africa

Southern Africa

West Africa -0 -Middle Africa

$\triangle$ Africa Linear Fitting

Fig. 2 Inter-annual variation of flood disaster annual frequency: 1990-2014

peaks in 1996-2000, 2006-2008, and 2010-2012. Although peaks did not strictly correspond to changes in El Niño and La Niña years, the time periods were in good agreement.

The Southern Oscillation is the atmospheric component of El Niño and is an oscillation in surface air pressure between the tropical eastern and the western Pacific Ocean waters. The strength of the Southern Oscillation is measured by using the Southern Oscillation Index (SOI) as computed from fluctuations in the surface air pressure difference between Tahiti (Pacific Ocean) and Darwin, Australia (on the Timor Sea, Indian Ocean) (Bureau of Meteorolo 2002). The inter-annual variation of SOI is opposite to that of the ONI, that is, when there is a low SOI, an abnormal increase in sea temperature in the eastern equatorial Pacific accompanies it and an El Niño event may ensue. Correlation coefficients (Table 1) indicate that annual frequencies of flood disaster during 1990-2014 in Africa, and its

Table 1 Correlation coefficients between SOI and flood annual frequency: 1990-2014

\begin{tabular}{lllllll}
\hline Spearman & Africa & North Africa & East Africa & Southern Africa & West Africa & Central Africa \\
\hline Correlation & $0.638^{* *}$ & 0.318 & 0.341 & $0.640^{* *}$ & $0.662^{* *}$ & $0.429 *$ \\
Sig. & 0.001 & 0.121 & 0.095 & 0.001 & 0.000 & 0.032 \\
\hline
\end{tabular}

* Significant at the 0.05 level; ** significant at the 0.01 level 
regions, are positively correlated with SOI. Correlation coefficients are significant at the 0.01 level in Africa as a whole, Southern Africa, and West Africa, and were significant at the 0.05 level in Central Africa. Results indicate that the larger the SOI (La Niña phenomenon becoming more obvious), the greater the annual precipitation may be, which will cause more flood disasters. Ward examined anomalies in flood risk between ENSO phases, and these anomalies reached statistical significance in river basins covering almost twothirds of the Earth's surface, showing that particularly strong anomalies exist in southern Africa and parts of western Africa in EI Niño years. In the Nile basins, including most North and East African countries, floods largely depend on the Blue Nile hydrology which is controlled by rainfall on the Ethiopian plateaus and is linked to the Southern Oscillation. When SOI is strongly positive, a large low-pressure system is centred on the Arabian Sea and heavy rains fall on the Ethiopian highlands. Conversely, when the SOI is strongly negative (an El Niño event), the low-pressure system is weakened or displaced to the east, and the summer monsoon rains are below normal.

The inter-annual variability of the mortality rate per 10 million people can reflect the intensity of flood disasters to a certain extent. As shown in Fig. 3, there are large-scale floods in East, Southern, Central, and North Africa during 1997 and 2001. The catastrophic flood in Somalia in 1997 killed 2311 people and affected another 1,230,000, which accounted for about $18 \%$ of the total population. Birkett pointed out that due to the influence of a strong El Niño event in 1997, equatorial easterlies were enhanced on the east coast of the Indian Ocean. This resulted in rapid cooling near the island of Sumatra acting
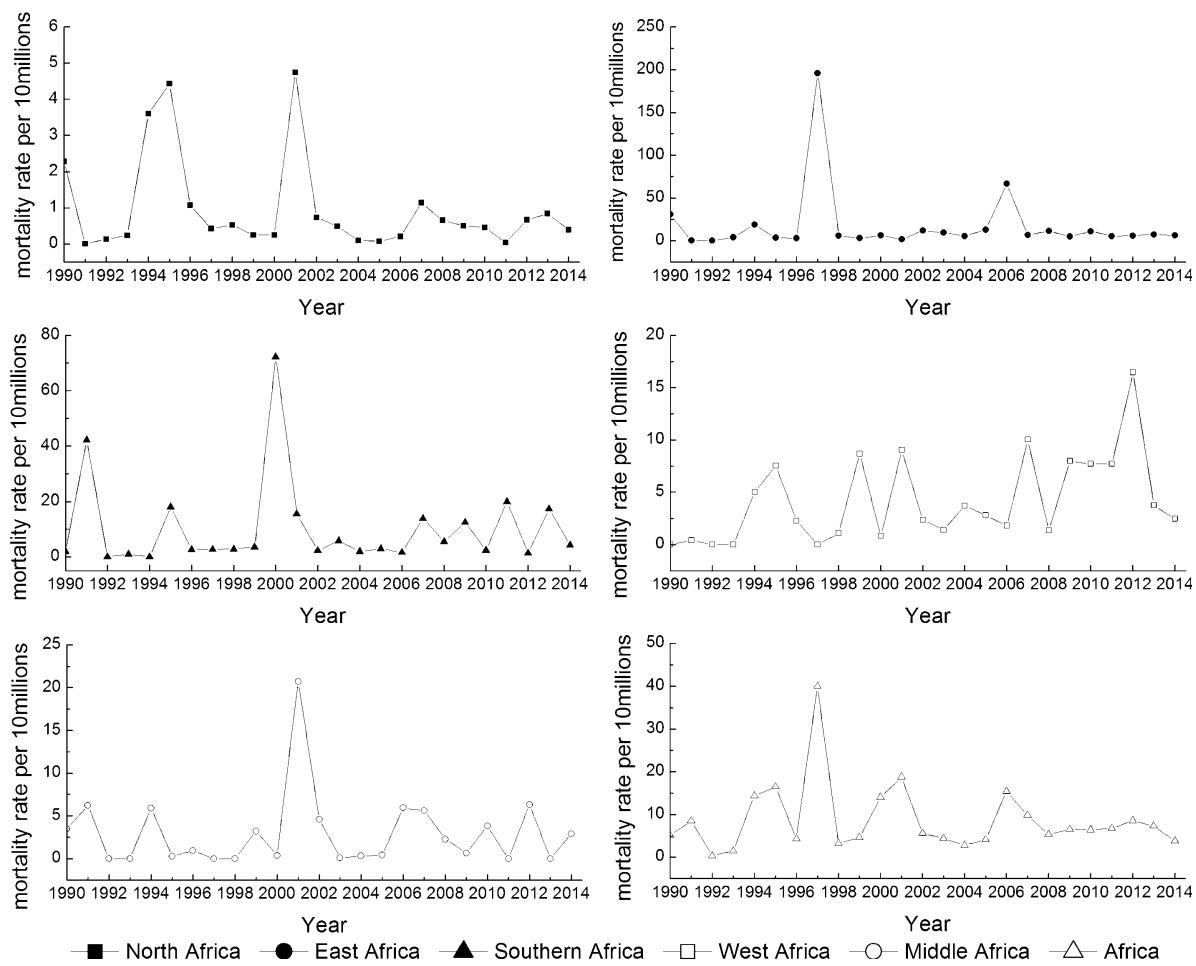

Fig. 3 Inter-annual variation of mortality rate per 10 million people: 1990-2014 
together with other weather events, while warming still continued on the West Coast, which would strengthen West-to-East gas water vapour transmission and cause abnormally heavy rainfall in the East African and West Indian Ocean (Birkett et al. 1999). International aid organisations said that this climate anomaly in late 1997 led to a flood disaster in coastal areas of Somalia. In 2000, continuous heavy rainfall occurred due to a typhoon in Mozambique and a serious flood emerged as the largest flood in the past 50 years. People affected accounted for about $27 \%$ of the total population, and the death toll and economic losses were large (Christie and Hanlon 2001). A large-scale flood disaster occurred in 2001 in Chad, resulting in 100 deaths, which was the largest death toll due to flooding since 1990. There was also a larger flood in 2001 in Algeria, resulting in 921 deaths and a loss of \$ 300 million (USD). In 2012, a severe flood occurred in Nigeria, due to the combined effects of strong precipitation and flood water released from upstream countries, resulting in about 400 deaths and economic losses of \$ 500 million (USD) (Agada and Nirupama 2015).

Due to the seasonal distribution of precipitations in different regions and seasonal fluctuations of ENSO, when the latter coincides with a regional rainy season, it may enhance precipitation and increase the flood frequency and intensity. On the contrary, if the latter coincides with a lower rainfall season, its influence on flood disasters is weaker. These can reasonably explain inter-annual differences of flood disaster frequencies and intensities in El Niño (La Niña) years.

\subsection{Spatial variations in flood disasters and the influencing factors}

Based on flood disaster records for 1990-2014, spatial distribution maps of annual average flood disaster frequency, deaths, affected people, and losses of African countries were drawn (Fig. 4). Ethiopia, Kenya, Somalia, and Tanzania in East Africa, Nigeria in Western Africa, and Libya, Sudan in Northern Africa are flood-prone countries. Ethiopia, Sudan, and Nigeria are located in the Blue Nile basin, Nile, and Niger River flood zones, respectively, and Somalia and Kenya are affected by coastal monsoons from the Indian Ocean. Flood-prone areas are consistent with the spatial distribution of deaths. There are many lakes in the East African Plateau, such as Victoria Nyanza, Lakes Tanganyika, Edward, and Albert. The precipitation and population densities around Victoria Nyanza are larger, especially in its western and northern parts. Di et al. studied the relationship between flood disaster intensities and flood zones, population growth and economic development in Africa, showing that the high concentrations of people, fast population growth, and disordered urbanisation in flood zones are highly correlated with flood mortality, which are main factors that affect the risk of death in Africa (Di et al. 2010). Annual average affected numbers of people and losses are mainly concentrated in the eastern region, and economic losses are larger in more developed countries, such as South Africa and Libya. Due to poverty levels in Central and East African countries being greater than in other regions, the economic losses in these areas are less though they occur with an apparently higher annual average frequency (Stein 2010).

To study factors influencing spatial distribution disparities of flood disaster situations in Africa, Pearson correlation analysis between flood disaster elements and other natural, social, and economic factors was chosen: results are shown in Table 2. The limitations in the interpretation of the spatial differences of flood disaster elements and unobvious correlations meant that precipitation and reservoir capacity were not included in Table 2 . The results showed that annual average frequencies of flood disaster are influenced by runoff, forest cover rate, per capita GDP, population, and urbanisation rate. The annual average 

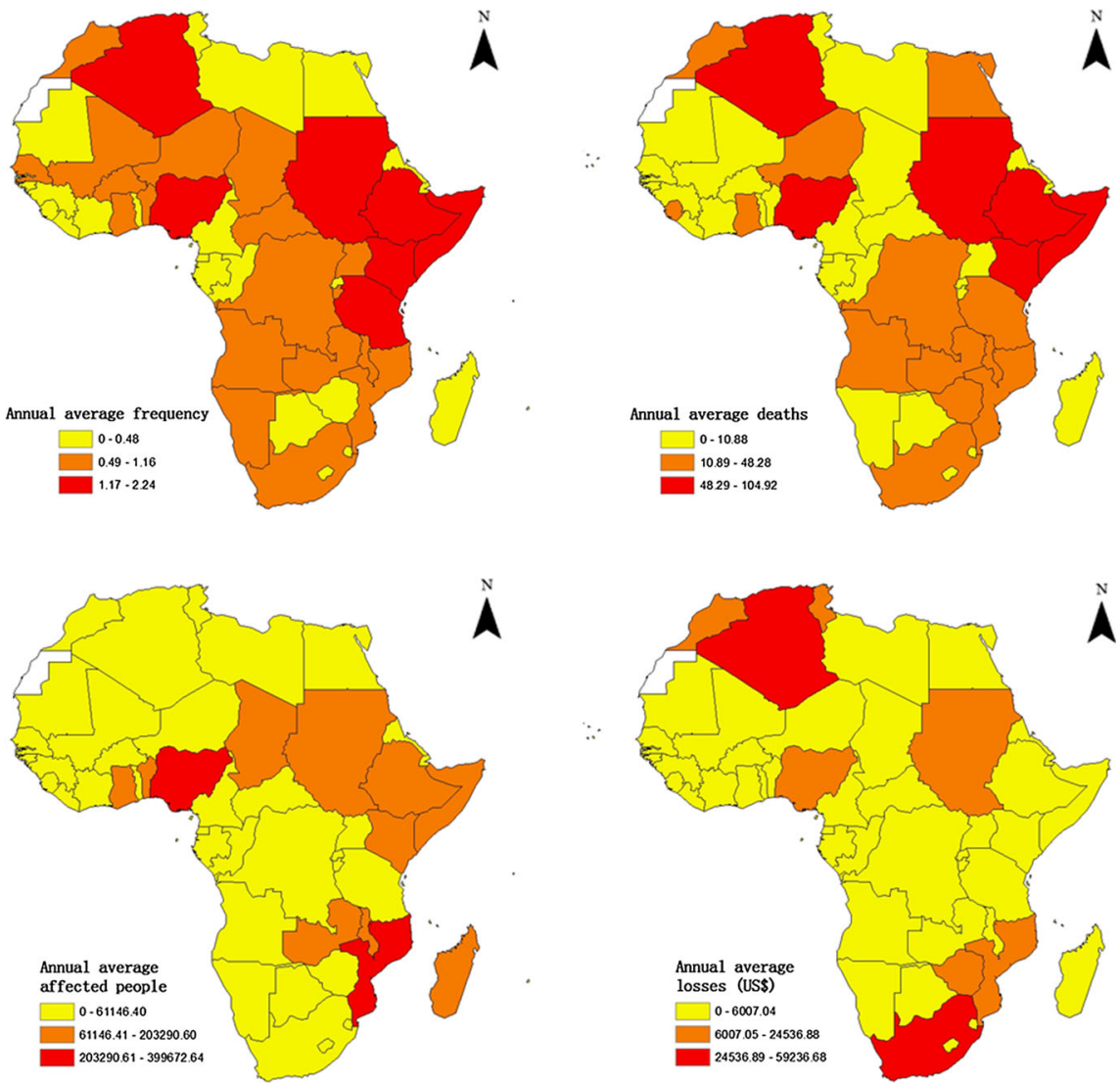

Fig. 4 Spatial distributions of flood disaster annual average statuses: 1990-2014

number of deaths is related to population and the annual average frequency of flood disasters. For one thing, frequency and intensity determine flood disaster deaths in a fundamental manner. For another, the more people a country has, the larger its population exposure to flood disaster is. Losses and people affected are significantly correlated with flood disaster frequencies and population. Runoff is a direct hazard factor causing floods and is comprehensively affected by climatic factors, such as precipitation, temperature, and evaporation (Song et al. 2015). Owing to being significantly positively related to runoff, the forest coverage rate shows a significant positive correlation with the occurrence frequency of flood disasters. Regional differences in the flood disaster situation in Africa are mainly determined by flood disaster frequency, which is positively correlated with losses, the number of deaths, and people affected. Per capita GDP and urbanisation rate are the most commonly used indicators to reflect the level of socio-economic developments. They both show significant negative correlations with flood frequency, indicating that flood control and reduction abilities may be stronger in economically developed, and highly urbanised, areas. In these areas, populations may be relatively concentrated in urban districts with improved infrastructures, and rural and other underdeveloped areas have relatively small populations, which thereby can reduce the degree of exposure and 


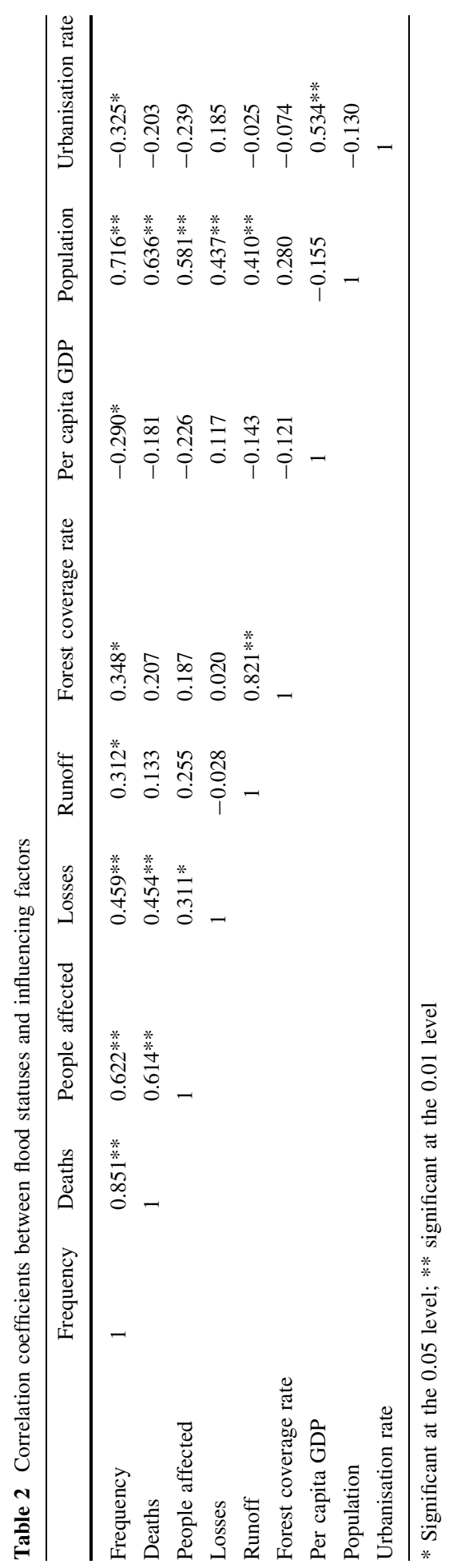


vulnerability to flood disaster. Rapid population growth generally increases population loads and may enhance vulnerability to flood disasters in African countries. Therefore, population is significantly positively correlated with losses, the number of deaths and people affected by floods.

\section{Conclusions}

Monthly variations of flood disasters in most regions, except North Africa, were consistent with that of monthly precipitation changes. Due to the effects of global scale climate change and general circulation anomalies, annual frequencies of flood disaster exhibited fluctuating upward trends in Africa and its regions from 1990 to 2014 and were positively correlated with SOI. Besides, peaks appeared with good agreement with ENSO interannual variations.

In terms of spatial distributions, Ethiopia, Kenya, Somalia, and Tanzania in East Africa, Nigeria in Western Africa, and Libya and Sudan in Northern Africa are flood-prone countries. The number of people affected and losses are mainly concentrated in the eastern region, and economic losses are larger in more developed countries, such as South Africa and Libya.

Regional differences in the rate of flood disaster occurrence are significantly correlated with runoff, the forest coverage rate, GDP per capita, population, and urbanisation rates in Africa. The numbers of death and people affected are mainly influenced by flood occurrences and population, while disaster losses are positively related to flood occurrence, the death toll, number of people affected, and population.

With continuous improvement in socio-economic status, the vulnerability of African countries to flood disasters will be reduced. However, due to global climate change and anomalies, annual frequencies of flood disasters may rise and result in increasing exposure to these risks. So flood disasters will still be an important risk factor affecting human health in Africa in the long term. In addition, many insect-borne infectious diseases and intestinal infectious diseases are prevalent in Africa, and frequent flood disasters may be accompanied by infectious diseases. Therefore, further study of the relationship between flooding and epidemics of infectious diseases in Africa is deemed worthwhile.

Acknowledgments This work was funded by the Key Project of the Knowledge Innovation Program of IGSNRR (Grant No. 2012SJ002) and the Program of National Science Infrastructure Platform (Grant No. 2013FY114600-3-1). The authors are grateful to Li Wang and Yuan Liu for their contribution to this research.

\section{References}

Agada S, Nirupama N (2015) A serious flooding event in Nigeria in 2012 with specific focus on Benue State: a brief review. Nat Hazards 77:1405-1414

Birkett C, Murtugudde R, Allan T (1999) Indian Ocean climate event brings floods to East Africa's lakes and the Sudd Marsh. Geophys Res Lett 26:1031-1034

Bureau of Meteorolo (2002). Climate glossary-Southern Oscilliation Index (SOI) http://www.bom.gov.au/ climate/glossary/soi.shtml. Accessed 31 Dec 2009

Christie F, Hanlon J (2001) Mozambique and the great flood of 2000. Can J Afr Stud 14:452-453

Di BG, Alberto M, Harry L, Demetris K, Luigia B, Günter B (2010) Flood fatalities in Africa: from diagnosis to mitigation. Geophys Res Lett 37:707-716 
He H, Lu H, Ou Y (2009) Flood characteristics of the Xijiang river basin in 1959-2008. Adv Clim Change Res 5:134-138

Jiang W, Li J, Wang L (2006) Compositive analysis of global flood disaster from 1950 to 2004. J Beijing Normal Univ 42:530-533

Kabanda TH, Palamuleni LG (2013) Land use/cover changes and vulnerability to flooding in the Harts catchment, South Africa South African geographical. J Being A Rec Proc S. Afr Geograph Soc 95:105-116

Meque A, Abiodun BJ (2014) Simulating the link between ENSO and summer drought in Southern Africa using regional climate models. Clim Dyn 44:1-20

Milly PC, Wetherald RT, Dunne KA, Delworth TL (2002) Increasing risk of great floods in a changing climate. Nature 415:514-517

Petroni F, Ausloos M (2007) High frequency (daily) data analysis of the southern oscillation index. Tsallis nonextensive statistical mechanics approach. Eur Phys J Special Topics 143:201-208

Sasaki W, Doi T, Richards KJ, Masumoto Y (2015) The influence of ENSO on the equatorial Atlantic precipitation through the Walker circulation in a CGCM. Clim Dyn 44:191-202

Song WZ, Jiang YZ, Lei XH, Wang H, Shu DC (2015) Annual runoff and flood regime trend analysis and the relation with reservoirs in the Sanchahe River Basin. China Quat Int 380-381:197-206

Stein H (2010) World Bank agricultural policies, poverty and income inequality in Sub-Saharan Africa. Camb J Regions Econ Soc 4:79-90

Tang XC, Yuan ZY (2010) The influence of the drought disaster caused by El Nino events in Guangdong Province in recent 60 years. Geograph Res 29:1932-1939

United Nations International Strategy for Disaster Reduction (2009) 2009 Global assessment report on disaster risk reduction: risk and poverty in a changing climate. Oriental Press, Manama

Veijalainen N, Lotsari E, Alho P, Vehviläinen B, Käyhkö J (2010) National scale assessment of climate change impacts on flooding in Finland. J Hydrol 391:333-350

Vormoor K, Lawrence D, Heistermann M, Bronstert A (2014) Climate change impacts on the seasonality and generation processes of floods in catchments with mixed snowmelt/rainfall regimes: projections and uncertainties. Hydrol Earth Syst Sci 11:6273-6309 